\title{
Article
}

\section{In situ generation of carbon dots within a polymer matrix}

Fernandes, Diogo Andre jardoso, Heslop, K.A., Kelarakis, Antonios, Krysmann, Marta and Estevez, L.

Available at http://clok.uclan.ac.uk/31443/

Fernandes, Diogo Andre jardoso, Heslop, K.A., Kelarakis, Antonios ORCID:

0000-0002-8112-5176, Krysmann, Marta ORCID: 0000-0002-8036-4925 and Estevez, L. (2020) In situ generation of carbon dots within a polymer matrix. Polymer, 188 (122159). ISSN 0032-3861

It is advisable to refer to the publisher's version if you intend to cite from the work. http://dx.doi.org/10.1016/j.polymer.2020.122159

For more information about UCLan's research in this area go to http://www.uclan.ac.uk/researchgroups/ and search for < name of research Group>.

For information about Research generally at UCLan please go to http://www.uclan.ac.uk/research/

All outputs in CLoK are protected by Intellectual Property Rights law, including Copyright law. Copyright, IPR and Moral Rights for the works on this site are retained by the individual authors and/or other copyright owners. Terms and conditions for use of this material are defined in the policies page.

\section{CLoK}

Central Lancashire online Knowledge www.clok.uclan.ac.uk

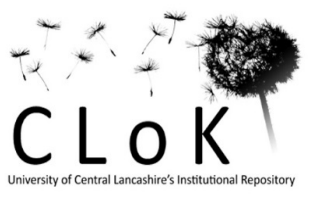




\title{
In situ generation of carbon dots within a polymer matrix
}

\author{
D. Fernandes ${ }^{\mathrm{a}, \mathrm{b}}$, K. A. Heslop ${ }^{\mathrm{a}}$, A. Kelarakis ${ }^{a^{*}}$, M.J. Krysmann ${ }^{\mathrm{c}}$, L. Estevez ${ }^{\mathrm{d}}$
}

${ }^{a}$ UCLan Research Centre for Smart Materials, School of Physical Sciences and Computing, University of Central Lancashire, Preston PR12HE, U.K.

${ }^{\mathrm{b}}$ Malvern Panalytical, Grovewood Road, Enigma Business Park, Malvern, Worcestershire WR14 1XZ, UK

${ }^{c}$ School of Pharmacy and Biosciences, University of Central Lancashire, Preston PR12HE, U.K.

${ }^{\mathrm{d}}$ Pacific Northwest National Laboratory, Richland, WA, USA

email: akelarakis@uclan.ac.uk, tel: 004417724172

\begin{abstract}
We disclose a green, cost and time effective approach to impart photoluminescent properties to a range of polymeric materials, an otherwise solvent-intensive and tedious process. Our strategy relies on the thermal treatment of ethanolamine (a carbon and nitrogen-rich precursor) well dispersed within a polymer matrix and gives rise to fluorescent C-dot based nanocomposites, without compromising the physicochemical characteristics of the matrix. The strategy affords at least $20 \%$ conversion of the precursor towards fluorescent nanoparticles, eliminates the use of toxic chemicals and is thoroughly compatible with melt processing technologies routinely used in industry. While we focus here on polyethylene (PE), polypropylene (PP) and polyethylene glycol (PEG) nanocomposites, the approach is general and applicable to a variety of thermally stable polymers. The C-dots formed in situ within the PEG matrix have diameters in the range 1-40 nm (as revealed by TEM) and exhibit quantum yield $11 \%$ in water compared to $3 \%$ for the PE-derived nanoparticles.
\end{abstract}

Keywords: Carbon dots; photoluminescence; nanocomposites 


\section{Introduction}

Carbon nanostructures, their derivatives and their composite materials are systematically explored in a variety of applications including 3-D printing [1], energy storage [2], electromagnetic wave shielding [3], lubricants [4], anticorrosion [5], antibacterial [6], pollutant adsorption [7], wound dressing [8], mechanical reinforcement [9-11] and metamaterials [12].

One of the most recent additions to the carbon family is the rapidly emerging class of photoluminescent carbogenic nanoparticles (otherwise known as carbon dots or C-dots) that show great potential for bioimaging, selective and sensitive biosensing, environmental monitoring, catalysis, photovoltaics and optoelectronics [13-17]. An increasing body of evidence suggests that $\mathrm{C}$-dots are biocompatible and nontoxic $[18,19]$, while they exhibit excitation wavelength dependent emission with intensity levels comparable to semiconducting quantum dots [20,21]. In addition to their colourful nature, they exhibit $\mathrm{pH}$ responsivity as well as colloidal and structural stability rarely seen in other photoactive compounds.

A distinct advantage of this class of nanoemitters is their facile preparation by means of electrochemical cutting [22], or oxidative decomposition of carbon structures including graphene [23], fibers [24], carbon nanotubes [25], carbon black [26], etc. Alternatively, welldefined C-dots are produced via pyrolytic treatment of natural products [27] (such as grass [28], fruit juice [29], eggs [30], rice residue [31]), synthetic materials [32,33] or suitable precursors [34]. The photoluminescence properties of aqueous dispersions of C-dots are sensitive to the presence of an electric field [35] and is typically improved via surface passivation and functionalization strategies [36] using amine terminated PEGylated chains [37], poly(ethylenimine) [38] and organosilanes [39].

Besides aqueous solutions, interest lies on the development of solid state hybrid materials such as C-dots based nanopowders [40-42], thin films [43,44] and polymer nanocomposites [45- 
50]. In principle, the preparation of C-dots based nanocomposites is realised by means of solution blending [46-50], use of precursor materials [45,51], layer by layer assembly $[43,44]$ and covalent guest-host conjugation [52]. To that end, preformed C-dots were mixed with polyaniline (PANI) in water and the PANI/C-dot nanocomposite was centrifuged out of the solution [46]. Likewise, preformed C-dots were mixed with PVA in water, followed by solvent evaporation to generate PVA/C-dot nanocomposite [47], while poly(vinyl butyral) was blended with C-dots in ethanol, leading to a transparent nanocomposite [49]. In a different approach, pyrrole was polymerised in the presence of $\mathrm{C}$-dots to generate electronically conductive polypyrrole/C-dot nanocomposite [51], while the precursors of both PDMS and C-dots were dispersed in THF before being thermally treated to generate PDMS/C-dot nanocomposite [45]. Following a guest-host conjugation, amine and carboxyl functionalized C-dots were covalently attached to carboxylated acrylonitrile butadiene latex [52].

In this study we report a solvent-free, time and cost-effective strategy to synthesize a range of C-dots based polymer nanocomposites. The method solely relies on the pyrolytic decomposition of ethanolamine (EA) within a polymer matrix and gives rise to colour-tuneable polymeric hybrids. We demonstrate here that our approach is compatible with standard meltprocessing technologies routinely employed in industry and, as such, it can facilitate the largescale production of a variety of fluorescent polymeric materials.

\section{Experimental}

\section{Synthesis of polymer nanocomposites}

Ethanolamine (EA) (boiling point=170 ${ }^{\circ} \mathrm{C}$ ), polyethylene (PE) with $\mathrm{M}_{\mathrm{w}}=3.5 \times 10^{4} \mathrm{~g} / \mathrm{mol}$, polyethylene glycol (PEG) with $\mathrm{M}_{\mathrm{w}}=10^{3} \mathrm{~g} / \mathrm{mol}$ and isotactic polypropylene (PP) with $\mathrm{M}_{\mathrm{w}}=$ $1.9 \times 10^{5} \mathrm{~g} / \mathrm{mol}$ were all purchased from Sigma-Aldrich. For the preparation of PE/C-dot nanocomposite (referred to as PE-hybrid), a mixture containing $1 \mathrm{wt} \%$ of EA in PE was 
enclosed in a glass vial and was heated under vigorous stirring at $160{ }^{\circ} \mathrm{C}$ for $30 \mathrm{~min}$, before the temperature was raised at $180{ }^{\circ} \mathrm{C}$ for another $30 \mathrm{~min}$ (the thermal treatment took place under ambient atmosphere). A similar protocol was followed for the preparation of PEG/C-dot nanocomposite (referred to as PEG-hybrid). Following the thermal treatment, the nanocomposites were left to crystallize at room temperature. Control samples were prepared by processing the polymers under identical conditions, but in the absence of EA. In addition, EA-derived C-dots were prepared under identical conditions, but in the absence of the polymer matrix. For the preparation of PP/C-dots nanocomposite, PP was thoroughly mixed with EA before being heated at $160{ }^{\circ} \mathrm{C}$ for 10 min and then being melt coextruded with a twin screw at $200{ }^{\circ} \mathrm{C}$ under nitrogen flow for another $5 \mathrm{~min}$.

To extract C-dots from the PEG-hybrid, the nanocomposite was placed into a SnakeSkin dialysis tubing membrane $\left(3.5 \times 10^{3} \mathrm{~g} / \mathrm{mol}\right.$ molecular weight cut-off $)$ and the polymer was dialysed against water for several weeks, while the dialysing water was renewed frequently (a control test indicated that the polymer can escape the membrane under similar conditions). To extract C-dots from the PE-hybrid, the ground nanocomposite was placed into a water container and was left under vigorous stirring for several days.
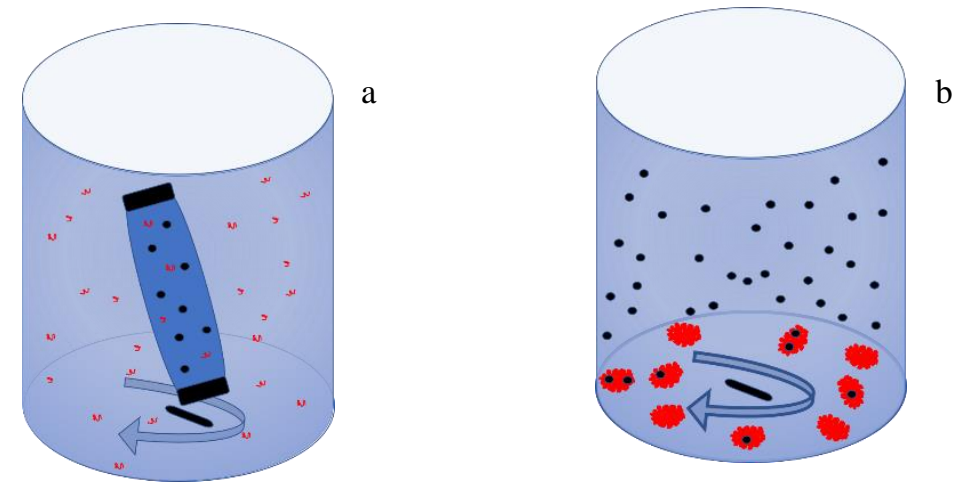

Scheme 1. Experimental setup for the extraction of: a) PEG-derived C-dots by means of dialysis against water (PEG is escaping via the membranes pores) and b) PE-derived C-dots by means of mechanical detachment (vigorous stirring) from the PE/C-dot nanocomposite in water (C-dots are detached mechanically and dispersed in a water) 
Fluorescence analysis

Fluorescence analysis was conducted on a Horiba Fluoromax spectrofluorometer and the samples were excited at wavelengths between $320-500 \mathrm{~nm}$, with $30 \mathrm{~nm}$ increment. For solidstate fluorescence measurements, the sample holder was positioned at a $30^{\circ}$ angle from the incident beam.

\section{Fluorescence imaging}

The fluorescence microscopy images were obtained using a Zeiss Axio Scope A1 microscope equipped with band-pass filters. Three excitation wavelengths were used with $\lambda_{\mathrm{ex}}=350,395$ and $590 \mathrm{~nm}$.

Fourier Transform Infra-Red (FTIR) spectroscopy

FTIR spectra were recorded using a Nicolet IR2000 spectrophotometer at room temperature. A total amount of 32 scans were run within a range of $3000-700 \mathrm{~cm}^{-1}$ at a resolution of $8 \mathrm{~cm}^{-1}$. Proton nuclear magnetic resonance $\left({ }^{1} \mathrm{H} N M R\right)$ spectroscopy

Samples were dissolved in $\mathrm{D}_{2} \mathrm{O}$ and ${ }^{1} \mathrm{H}$ NMR spectra were collected using a Bruker spectrometer operating at $400 \mathrm{MHz}$.

\section{Elemental Analysis}

A Thermo Scientific Flash 2000 CHNS Elemental Analyzer was calibrated using cysteine and methionine as standard materials. The samples were weighted in tin capsules and their $\mathrm{CHN}$ elemental content determination was repeated three times.

Differential scanning calorimetry (DSC) 
DSC analysis was conducted on a TA DSC Q2000 calorimeter at a scan rate of $5{ }^{\circ} \mathrm{C} / \mathrm{min}$ over the temperature range $0^{\circ} \mathrm{C}$ to $80^{\circ} \mathrm{C}$ and $0^{\circ} \mathrm{C}$ to $160^{\circ} \mathrm{C}$ for $\mathrm{PEG}$ and $\mathrm{PE}$ based materials, respectively. For clarity, only the second heating scans are displayed.

\section{Transmission Electron Microscopy (TEM)}

One drop of C-dot dispersion in ethanol was deposited on a carbon coated copper grid. TEM images were obtained using a Tecnai F20 TEM/STEM from Fisher operated at $200 \mathrm{kV}$. Digital imaging was accomplished via an eagle camera and TIA software.

\section{Dynamic Light Scattering (DLS)}

DLS measurements were performed on a Malvern Panalytical Zetasizer Ultra, with a $10 \mathrm{~mW}$ $633 \mathrm{~nm}$ He-Ne laser source on a backscatter angle of detection with a narrow band filter fitted in to mitigate fluorescence detection. Measurements were taken at $25^{\circ} \mathrm{C}$, on $5 \mathrm{mg} / \mathrm{mL}$ solutions using a disposable plastic cell. Attenuation, measurement duration and laser focus position were set as automatic for all measurements. Adaptive correlation as used as default, and results displayed refer to Steady-State data only unless stated otherwise.

Nanoparticle Tracking Analysis (NTA)

NTA was performed on a Malvern Panalytical Nanosight NS300 using a $405 \mathrm{~nm}$ blue laser source. Data was recorded using NTA software version 3.4 and camera levels were optimized for each measurement. Temperature was set to $21^{\circ} \mathrm{C}$, and 3 runs of $60 \mathrm{~s}$ at a rate of $25 \mathrm{fps}$ were measured for each sample.

Optical microscopy (OM) characterization

Leico MC170 HD DMLM optical microscopy equipped with a Mettler Toledo FP82HT hot stage was used for characterize the crystallisation process of PEG on a glass surface. 


\section{Rheology}

The rheological properties were determined on a controlled strain rate parallel plate rheometer (AR2000, TA instruments, USA), using $25 \mathrm{~mm}$ diameter circular plates, with a gap of $6 \mathrm{~mm}$. The frequency scanning experiments were conducted with a strain of $1 \%$ and a fixed frequency of $0.1 \mathrm{rad} \mathrm{s}^{-1}$.

\section{Results and Discussion}

PE and PP were selected in this study because they represent two of the most common thermoplastics used in a variety of everyday products. Substantial amounts of those polymers are processed and reprocessed (recycled) by means of melt extrusion during which, in principle, our approach can be adopted. The equally popular PEG was selected given that its hydrophobic nature contrasts that of PE and PP and serves as a proof of concept demonstration on the versatility and generality of our method.

As detailed in the experimental session, PEG and PE were thermally treated with $1 \mathrm{wt} \%$ EA (at $160{ }^{\circ} \mathrm{C}$ for $30 \mathrm{~min}$ followed by further heating at $180{ }^{\circ} \mathrm{C}$ for another $30 \mathrm{~min}$ ) to give rise to PEG/C-dot and PE/C-dot nanocomposites, respectively. The PEG/C-dot nanocomposite was placed in a snake skin membrane with molecular cut off $3.5 \times 10^{3} \mathrm{~g} / \mathrm{mol}$ (i.e. much larger than the polymer size $\mathrm{M}_{\mathrm{w}}=10^{3} \mathrm{~g} / \mathrm{mol}$ ) to promote polymer dialysis against water, while C-dots remained inside the membrane. The PE/C-dot nanocomposite was fine grinded and was placed into a water container under vigorous stirring to facilitate the dispersion of C-dots.

The TEM image of the PEG derived C-dots is shown in Figure 1 and reveals the presence of spherical nanoparticles with diameters $10-40 \mathrm{~nm}$, while the lack of well-resolved lattice fringes might indicate the amorphous nature of the carbogenic cores. The large size distribution of the particles is consistent with the overall simplicity and the template-free nature of the synthetic 
method, coupled with the lack of any purification and size-exclusion steps. Although, C-dots are typically described as spherical nanoparticles with size less than $10 \mathrm{~nm}$, much larger C-dots with average diameter in excess of $40 \mathrm{~nm}$ have been derived, for example, via the pyrolytic decomposition of biomass $[53,54]$. NDA data recorded for PEG/C-dot aqueous dispersions is dominated by a broad peak that centres around $\mathrm{D}_{\mathrm{h}}=103 \mathrm{~nm}$ (Figure 2a). The normalized intensity fraction distributions of apparent hydrodynamic diameter $\left(\mathrm{D}_{\mathrm{h}}\right)$ for aqueous dispersions of PEG/C-dots reveal the coexistence of particles with $\mathrm{D}_{\mathrm{h}}=5.2 \mathrm{~nm}$ along with particles with $D_{h}=125 \mathrm{~nm}$ (Figure $2 \mathrm{~b}$ ). For reference it is noted that the pyrolysis of EA in the absence of the polymer matrix, but following otherwise identical protocols, gives rise to particles with $\mathrm{D}_{\mathrm{h}}=7 \mathrm{~nm}$ (Figure $\left.2 \mathrm{c}\right)$.

In general, the formation of spherical carbogenic nanoparticles by means of pyrolytic decomposition of precursor materials relies on fragmentation, polymerization, condensation and aromatization reactions. A previous study suggested that the formation of EA derived Cdots proceeds through an initial oxidation reaction followed by the polymerization step (colour turns into yellow) when a dense population of $\mathrm{C}=\mathrm{O}$ and $\mathrm{N}=\mathrm{O}$ is formed and, ultimately, a carbonization step (colour turns into black) [55]. At the same time, PEG macromolecules with varying molecular weights have been subjected to simple hydrothermal treatments to generate water-dispersible $\mathrm{C}$-dots with average size within the range 2-7 $\mathrm{nm}[56,57]$. The synthesis of this type of C-dots is triggered by the chain cleavage and oxidation of PEG molecules (colour turns into pale yellow) and proceeds through the formation of clusters and core-shell structures (colour turns into dark brown) [56]. We note that in our study the initially white PEG/EA melt adopted a yellow coloration after $10 \mathrm{~min}$ of heating at $160{ }^{\circ} \mathrm{C}$ that remained unaltered up to the end of the treatment, indicating that the polymeric chains do not undergo carbonization.

Figure 3 compares the ${ }^{1} \mathrm{H}$ NMR spectrum of PEG/C-dot nanocomposite with PEG (showing a multiplet at $3.7 \mathrm{ppm}$ ) and EA (showing peaks at 3.7 and $2.8 \mathrm{ppm}$ attributed to the $\mathrm{CH}_{2}$ protons 
of the $-\mathrm{CH}_{2} \mathrm{OH}$ and $-\mathrm{CH}_{2} \mathrm{NH}_{2}$ groups, respectively. Since the characteristic peaks of EA are not detected in the nanocomposite, it is clear that no traces of EA remained entrapped within the polymer matrix. Moreover, the spectra of PEG and PEG/C-dot nanocomposite appear identical, thus excluding the occurrence of any PEG-EA bonding along with the possibility of any pronounced matrix degradation.

Both PEG/ 5wt\% EA and PE/ 5wt\% EA precursor mixtures contain 1.15 wt $\%$ nitrogen, but elemental analysis indicated that the C-dot nanocomposites (derived via the pyrolytic treatment of the precursor blends) contain $0.32 \mathrm{wt} \%$ and $0.23 \mathrm{wt} \%$ nitrogen, respectively. This observation points to $28 \%$ and $20 \%$ conversion of EA to C-dots in PEG/-dot and PE/C-dot nanocomposites, respectively. For reference, it is noted that the pyrolysis of EA under identical condition but in the absence of polymer, yields $9 \%$ carbogenic material. It seems reasonable to assume that dispersion of EA to a polymeric matrix reduces its volatilization, thereby improving the yield in terms of C-dot formation.

The FTIR spectrum (black line in Figure 4) of the C-dots derived from the PEG based nanocomposite shows peaks centred at $3482 \mathrm{~cm}^{-1}, 2883 \mathrm{~cm}^{-1}, 1639 \mathrm{~cm}^{-1}, 1464 \mathrm{~cm}^{-1}, 1342 \mathrm{~cm}^{-}$ 1, $1107 \mathrm{~cm}^{-1}, 956 \mathrm{~cm}^{-1}$ and $852 \mathrm{~cm}^{-1}$, which can be ascribed to $\mathrm{O}-\mathrm{H}$ stretching, $\mathrm{C}-\mathrm{H}$ bending, $\mathrm{N}-\mathrm{C}=\mathrm{O}$ stretching, $\mathrm{CH}_{2}$ bending, $\mathrm{C}-\mathrm{H}$ bending, $\mathrm{C}-\mathrm{O}$ stretching symmetrical and antisymmetrical and C-O-C stretching, respectively [58-60]. Interestingly, a similar set of peaks is observed for the neat PEG, indicating strong physisorption of the polymeric chains to the Cdot surface. The FTIR spectrum (red line in Figure 3) of the C-dots extracted from the PE matrix shows peaks centred at $3324 \mathrm{~cm}^{-1}, 1642 \mathrm{~cm}^{-1}, 1399 \mathrm{~cm}^{-1}, 1218 \mathrm{~cm}^{-1}, 1056 \mathrm{~cm}^{-1}$ and 551 $\mathrm{cm}^{-1}$, ascribed to $\mathrm{O}-\mathrm{H}$ stretching, $\mathrm{C}=\mathrm{O}$ stretching, $\mathrm{CH}_{2}$ bending, $\mathrm{C}-\mathrm{C}$ symmetrical and antisymmetrical stretching and O-H out-of-plane bending stretching, respectively. Conversely, the spectrum of neat PE is dominated by the peaks arising from the C-H bond stretching (at 2915 and $2848 \mathrm{~cm}^{-1}$, for symmetrical and anti-symmetrical, respectively), scissoring $\left(1466 \mathrm{~cm}^{-1}\right)$ and 
rocking deformation $\left(719 \mathrm{~cm}^{-1}\right)$ [61]. This observation points to the self-passivation of pyrolytically prepared C-dots that is known not only to improve quantum yield but also to enhance dispersibility in a variety of media $[62,63]$.

The presence of those polar groups to the surface of the PEG and PE extracted C-dots, renders the nanoparticles dispersible in water. The photoluminescence (PL) spectra of the aqueous suspensions (shown in Figures 5a and b, respectively) are consistent with the characteristic behaviour of C-dots that show excitation wavelength-dependent emission with descending intensities at longer excitation wavelengths. The maximum PL intensity is observed at $\lambda_{\mathrm{ex}}=380$ $\mathrm{nm}$ and $\lambda_{\mathrm{ex}}=350 \mathrm{~nm}$ for PEG and PE-derived nanoparticles, respectively. An additional PL mode is active at low $\lambda_{\text {ex }}$ that has been previously ascribed to the presence of molecular fluorophores [64]. The quantum yield $(\Phi)$ (calculated against anthracene in ethanol) for PEG and PE-extracted nanoparticles in water was estimated to be $11 \%$ and $3 \%$, respectively, compared to $7 \%$ for the EA-derived C-dots (that exhibit a narrow size distribution that centres around $7 \mathrm{~nm}$ as shown in Figure 2c), while in previous studies the $\Phi$ of PEG-derived C-dots vary from 2.5 [54] to $38 \%$ [57].

In analogy, the solid-state fluorescence spectra of the PEG/C-dots and PE/C-dots (shown in Figures $5 \mathrm{c}$ and d, respectively) display strong and broad excitation-dependent emission peaks, while the neat polymers show minimal level of fluorescence. The maximum intensity is observed at $\lambda_{\mathrm{ex}}=380 \mathrm{~nm}$ for both PEG and PE based nanocomposites. The PL intensity of the PE based nanocomposite increased with the amount of added EA and reached a plateau at 5 wt $\%$ EA. The exact features of the complex PL mechanism of C-dots is currently under investigation, but possible contributions arise from quantum confinement presumably associated with the presence of $\mathrm{sp}^{2}$ islands within the $\mathrm{sp}^{3}$ network, edge and surface defects, crosslink enhanced emission and the presence of molecular chromophores $[65,66]$. In terms of heteroatom doping, it has been shown that incorporation of more electronegative atoms (e.g. 
$\mathrm{N})$ leads to blue shifted emissions, while introduction of less electronegative atoms (e.g. S) leads to red shifted emissions [67].

The optical microscope images shown in Figure 6 provide a clear overview of the pronounced changes in the crystallization patterns induced by $\mathrm{C}$-dots. While the neat PEG is crystallised into well-defined radial spherulites with radii in the order of several micrometers, those superstructures are diminished in the presence of C-dots. Similar effects observed in a variety of polymer based nanocomposites have been attributed to the nucleating efficiency of the nanofillers that impose constrains to the propagation of spherulites [68]. Interestingly, while single-walled carbon nanotubes [69] and clay nanoplatelets [70] tend to supress the crystallization of PEG, our results indicate that the crystallization temperature and the associate enthalpy of crystallization remain essentially unaltered for the PEG matrix in the presence of C-dots (Figure 7a). Similar trends were observed for the PE/C-dot nanocomposite (Figure 7b).

The small-amplitude oscillatory frequency scan of the PEG at $75^{\circ} \mathrm{C}$ is characteristic of a highly viscous system (Figure 8a), while the PEG/C-dot rheological behaviour reveals significant deviations from the ideal melt behaviour (Figure 8b). Those rheological effects are typical for nanocomposites and have been attributed to the revolution of an interconnected (and eventually percolated) network of polymer-swollen nanoparticles that actually function as crosslink centres.

To demonstrate the potential of this approach $1 \mathrm{wt} \%$ of EA was introduced to PP and was melt processed using a twin extruder. As shown in Figure 9a, the nanocomposite thus prepared exhibits remarkable colour-tunability and emits within the blue, green and red region upon irradiation with violet, blue and green light, respectively. For comparison, PEG/C-dot nanocomposites irradiated under identical conditions are also displayed in Figure $9 \mathrm{~b}$.

Tuneable light emission has been previously reported for C-dots polymeric hybrids prepared by solution blending. For example, preformed C-dots and polyaniline were co-dispersed in 
water to generate a highly selective and sensitive nanocomposite for the detection of $\mathrm{Hg}^{2+}$ [46], while preformed C-dots were co-dispersed with poly(methyl methacrylate) in DCM or with polyvinyl alcohol in water to generate light-emitting films [71]. An interesting study describes the one-pot synthesis of polydimethylsiloxane /C-dot films by dispersing the C-dots precursor, the silicon elastomer base and the curing agent in THF [45].

The synthesis of chromophoric units and their incorporation to macromolecular materials is a rather tedious and solvent intensive procedure. Typically, the preformed dyes are covalently bonded with the polymeric chains or, alternatively, they are dispersed within the matrix by means of solution blending or melt-mixing [72]. In analogy, the incorporation of preformed Cdots within the polymer matrix unavoidable involves a number of steps including the synthesis, purification and surface treatment of the nanoparticles, followed by a suitable mixing process. By design, our single-step approach not only eliminates the use of solvents that are essential when nanoparticles are incorporated to polymers via solution blending, but it also circumvents issues related to pronounced particle flocculation/agglomeration oftentimes encountered in nanocomposite melts [73]. The strategy can facilitate the development of composite materials that capitalise not only on the fluorescent properties of C-dots, but also on their supreme antimicrobial [74] and catalytic properties [75]. Finally, it is noted that the systematic exploration of a wide range of precursor materials (such as organic amines, urea, organic acids and their mixtures) is vital in order to optimise the quantum yield of the in situ generated nanoparticles, while the use of thermo-oxidative stabilisers might expand the gallery of suitable polymer matrixes.

\section{Conclusion}

The synthesis of fluorophore units and their incorporation to polymeric materials can be challenging and solvent-intensive. To that end, we present a cost-effective preparation method to generate a range of highly fluorescent polymeric materials comprising low concentrations 
of C-dots. The strategy relies on the pyrolytic decomposition of suitable carbon rich precursors well-dispersed within the polymer host that are thermally converted in situ into highly fluorescent nanoemitters. Our data indicate that the nature of the polymer matrix has a significant effect on the quantum yield of the C-dots as well as the yield of the formation reaction. Although, our approach presents challenges related to the accurate control of the size of C-dots, it is thoroughly compatible with standard industrial processing such as hot melt extrusion and, thus, can allow the large-scale production of a wide range of fluorescent materials. Clearly, the applicability of the method is limited to polymeric matrixes that show good wetting against the liquid precursor and can withstand heat treatment. A detailed characterization of the polymeric materials used remains outside the scope of this study, however our results indicate that pronounced decomposition of the matrices should be excluded. In terms of environmental friendliness, our approach eliminates the use of solvents, while resulting in the formation of highly fluorescent C-dots nanoparticles that show minimal toxicity. 


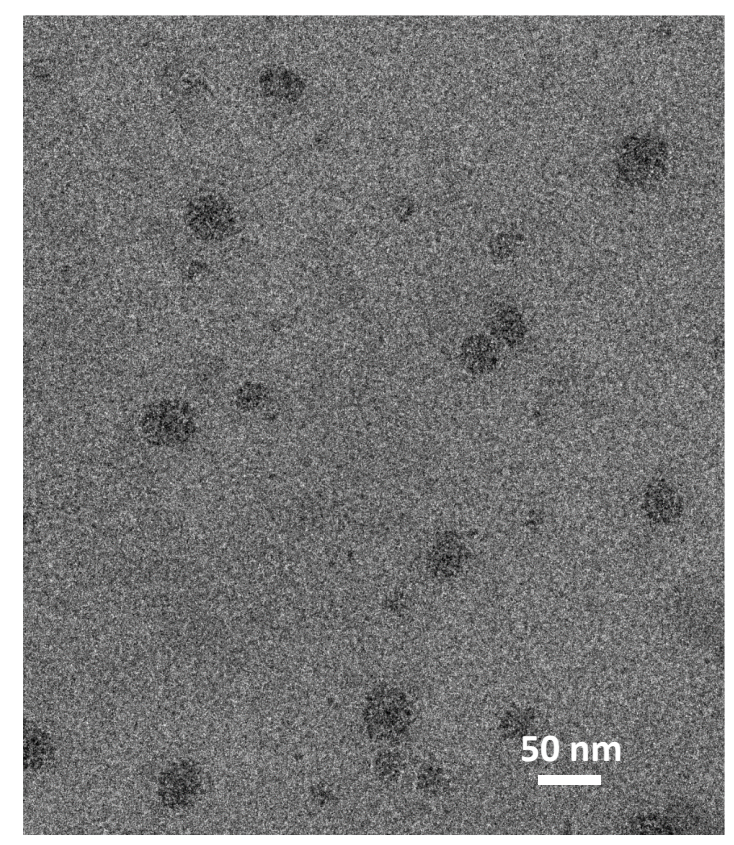

Figure 1. TEM image of the C-dots extracted from PEG/C-dot nanocomposite. 

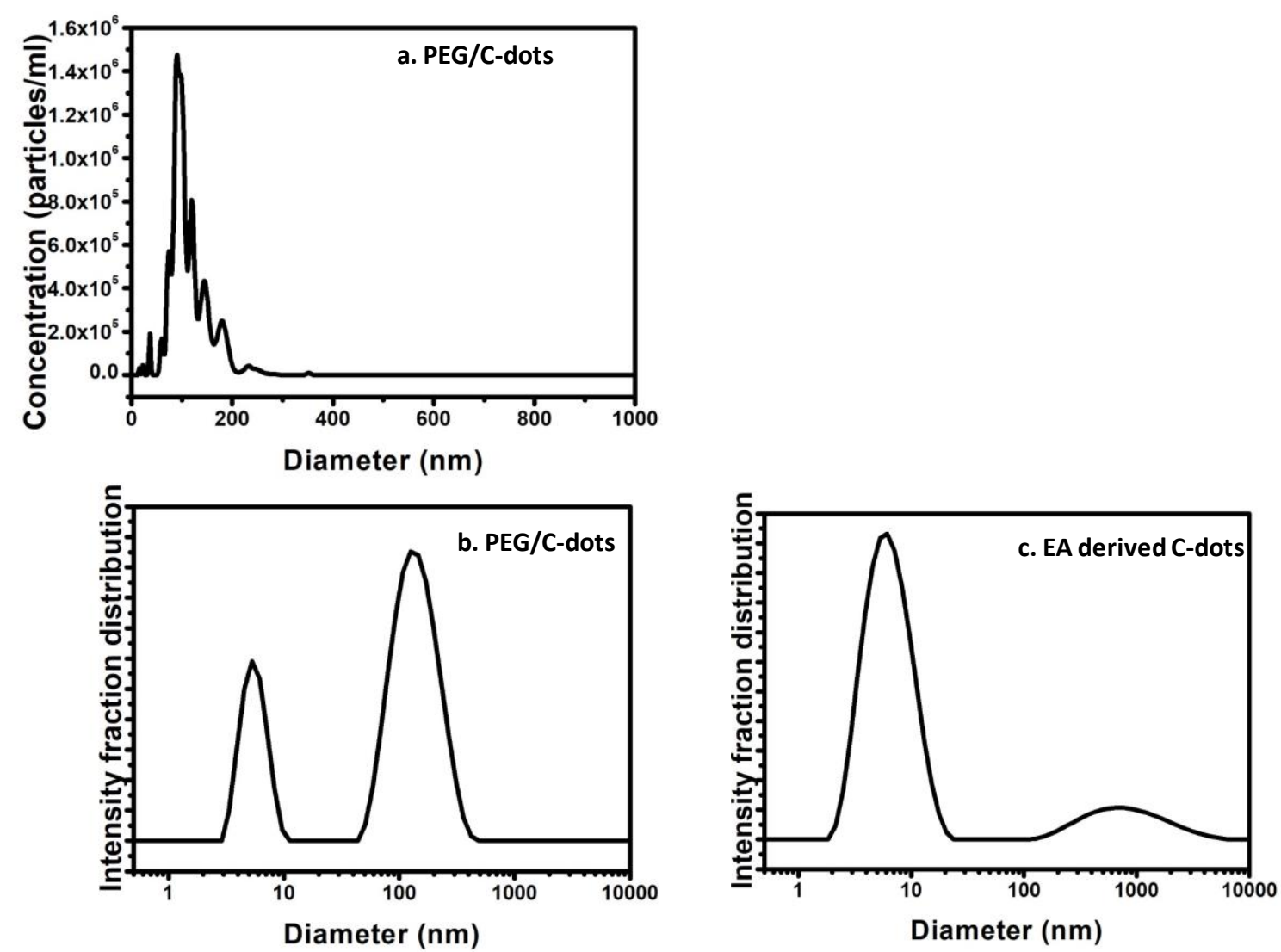

Figure 2. (a) Size distribution profiles of $2 \mathrm{wt} \%$ aqueous dispersions of PEG/C-dots determined by $\left(\mathrm{T}=21{ }^{\circ} \mathrm{C}\right)$ NTA. Normalized intensity fraction distributions of apparent hydrodynamic diameter $\left(\mathrm{T}=25{ }^{\circ} \mathrm{C}\right)$ for $2 \mathrm{wt} \%$ aqueous dispersions of: (b) PEG/C-dots and (c) EA-derived C-dots. 


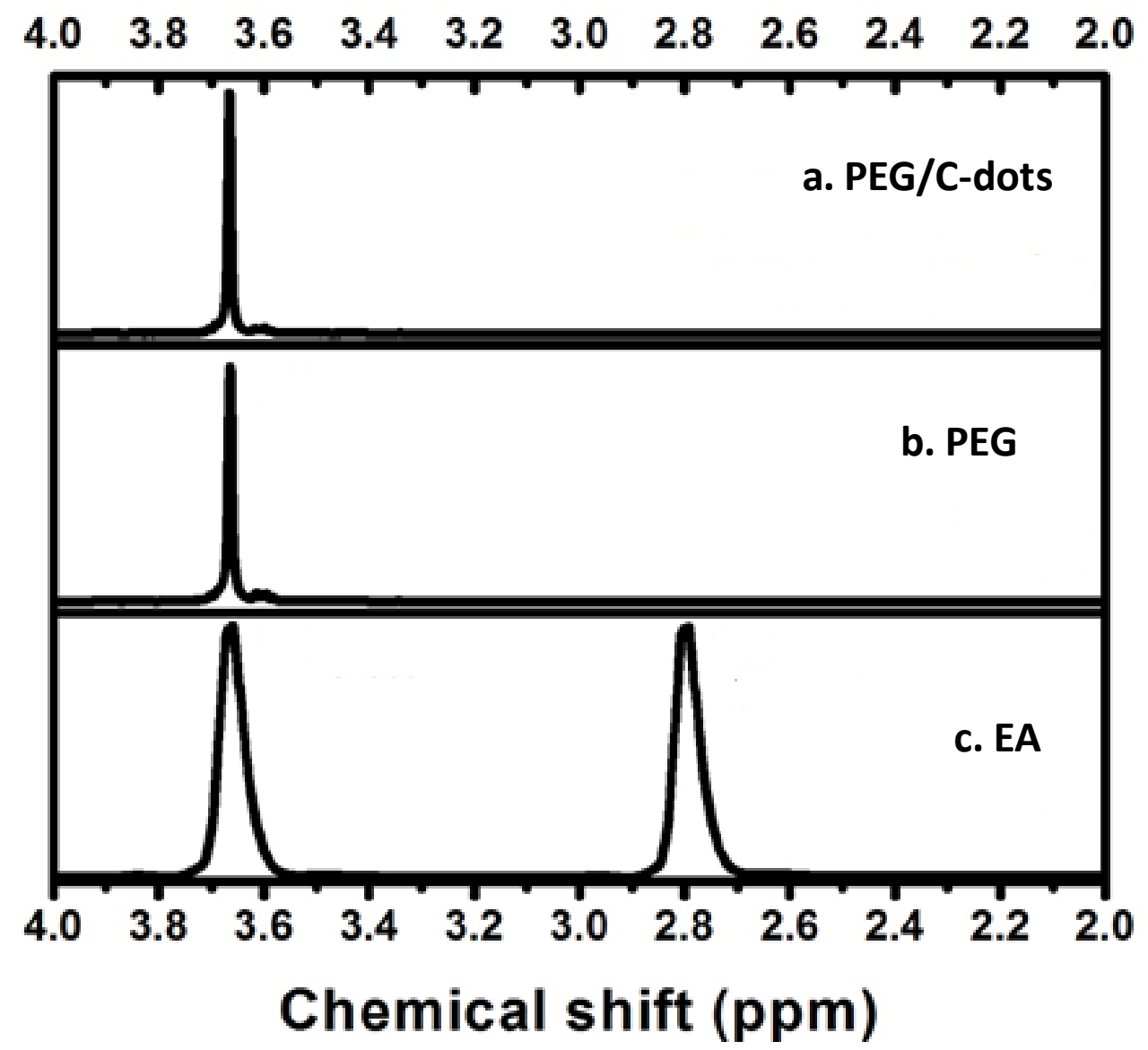

Figure 3. ${ }^{1} \mathrm{H}$ NMR spectra of: (a) PEG/C-dot, (b) PEG and (c) EA in $\mathrm{D}_{2} \mathrm{O}$ 


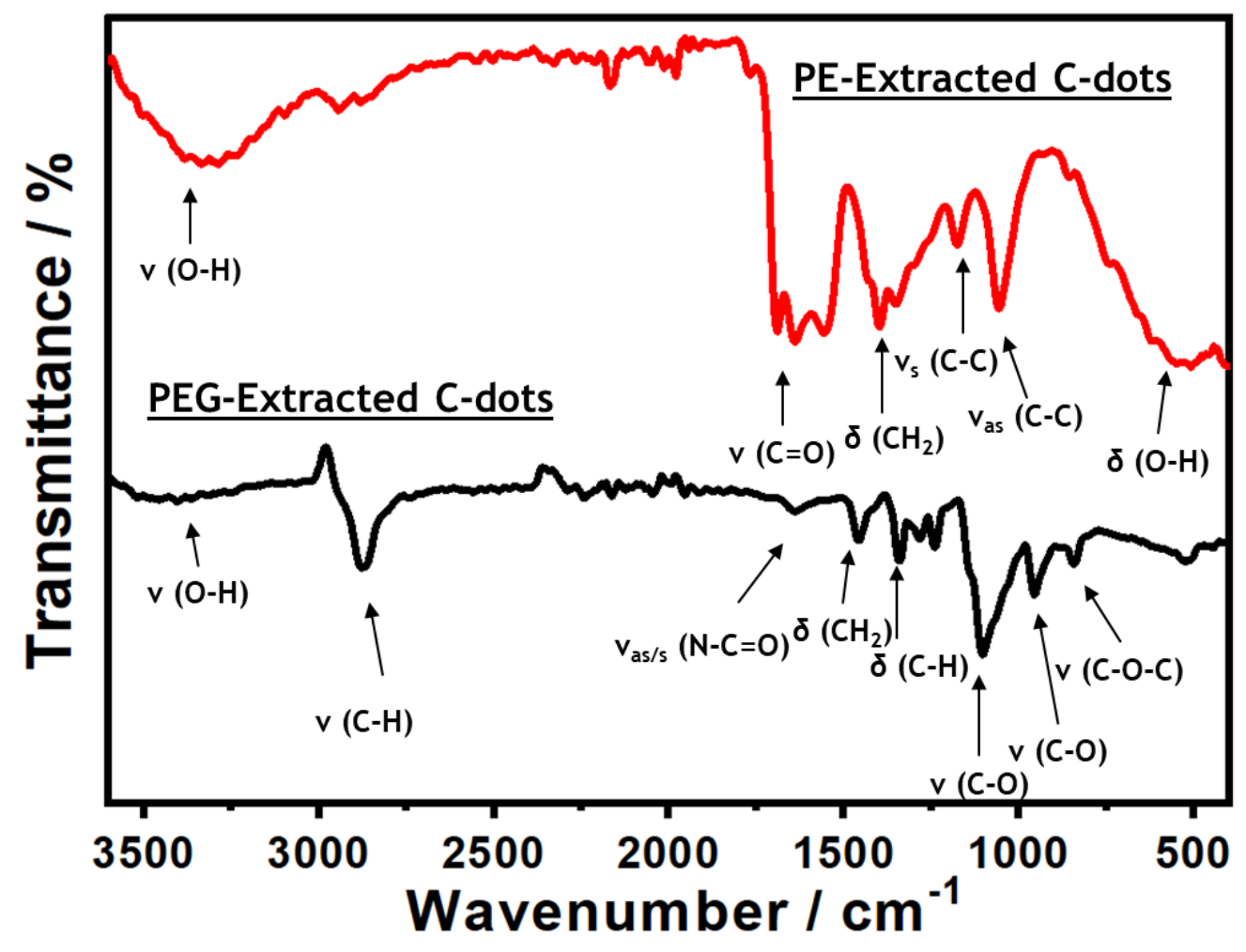

Figure 4. FTIR spectra of C-dots extracted from: (a) PEG (black line) and (b) PE (red line) nanocomposites. 
a. PEG extracted C-dots in water

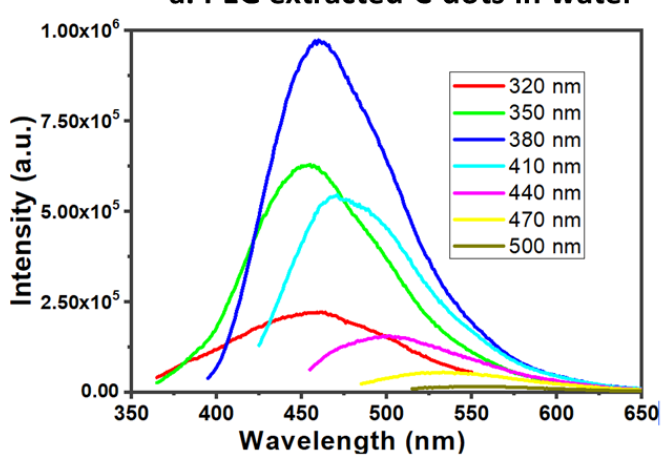

c. PEG/C-dots

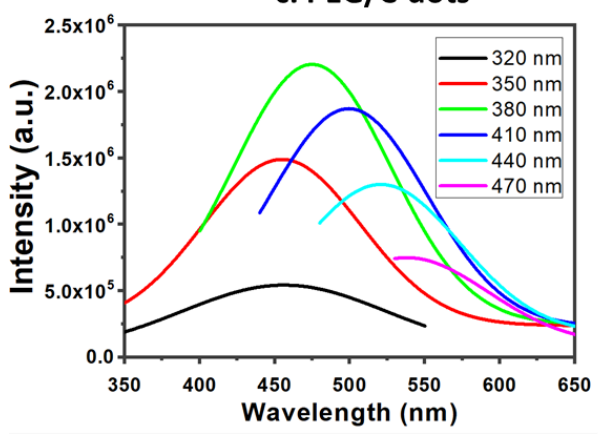

b. PE extracted C-dots in water

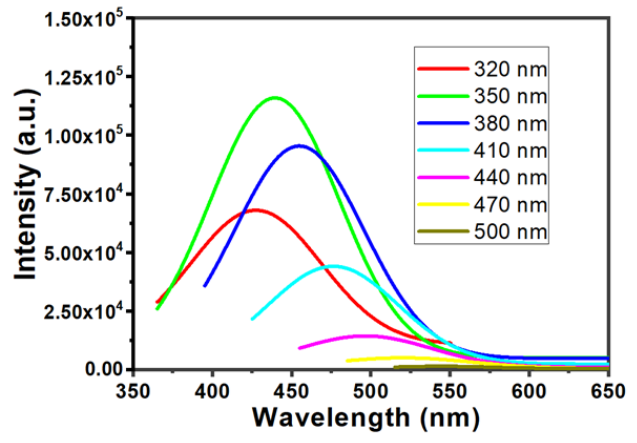

d. PE/C-dots

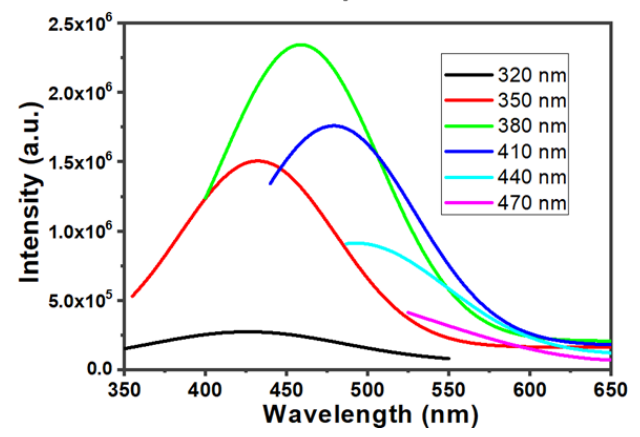

Figure 5. Fluorescence emission spectra (under the excitation wavelengths indicated) of 0.1 $\mathrm{mg} / \mathrm{ml}$ aqueous dispersions of C-dots extracted from: (a) PEG and (b) PE matrix. Solid-state fluorescence spectra of: (c) PEG/ C-dot and (d) PE/C-dot nanocomposite. 

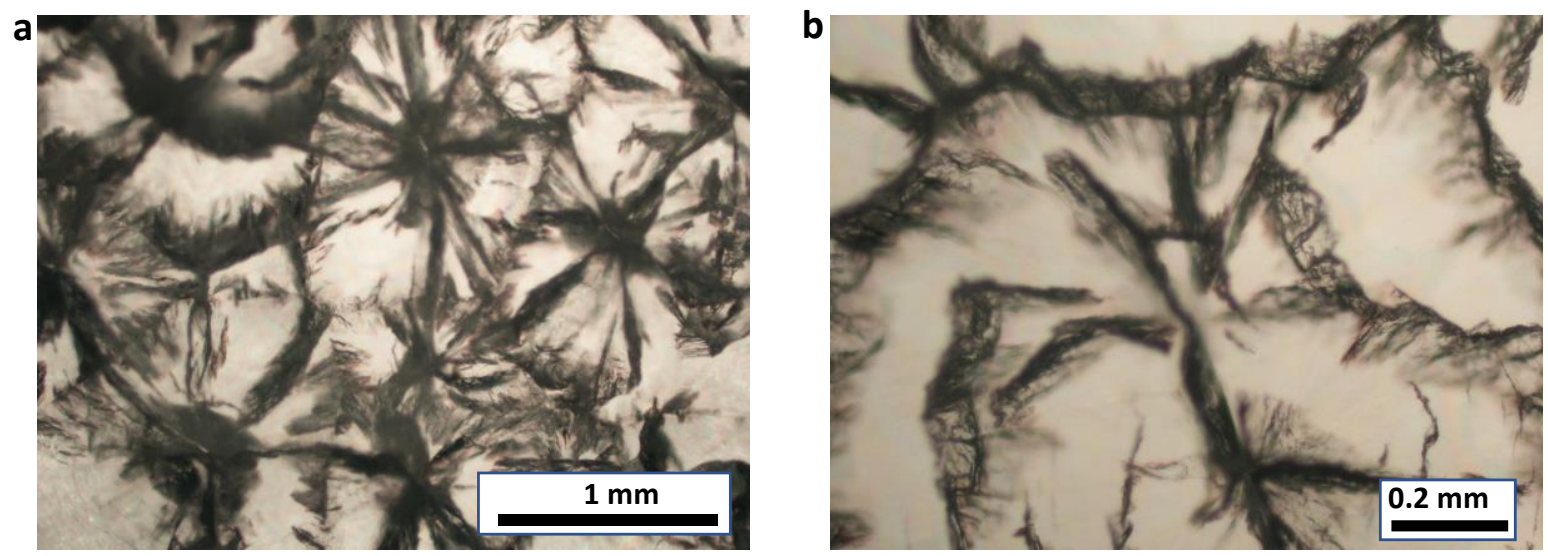

C
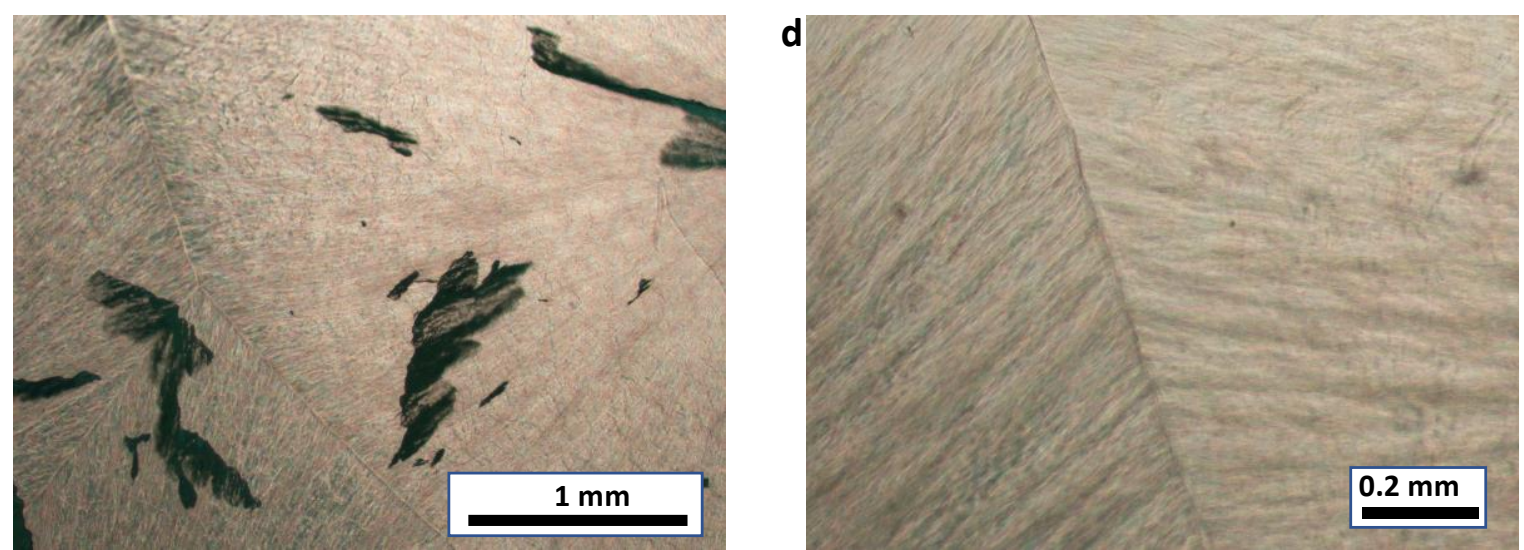

Figure 6. Polarised optical microscope images of; a and b) PEG well-defined spherulites and c and d)PEG/C-dot nanocomposite crystallised at $22{ }^{\circ} \mathrm{C}$ on a glass surface. 

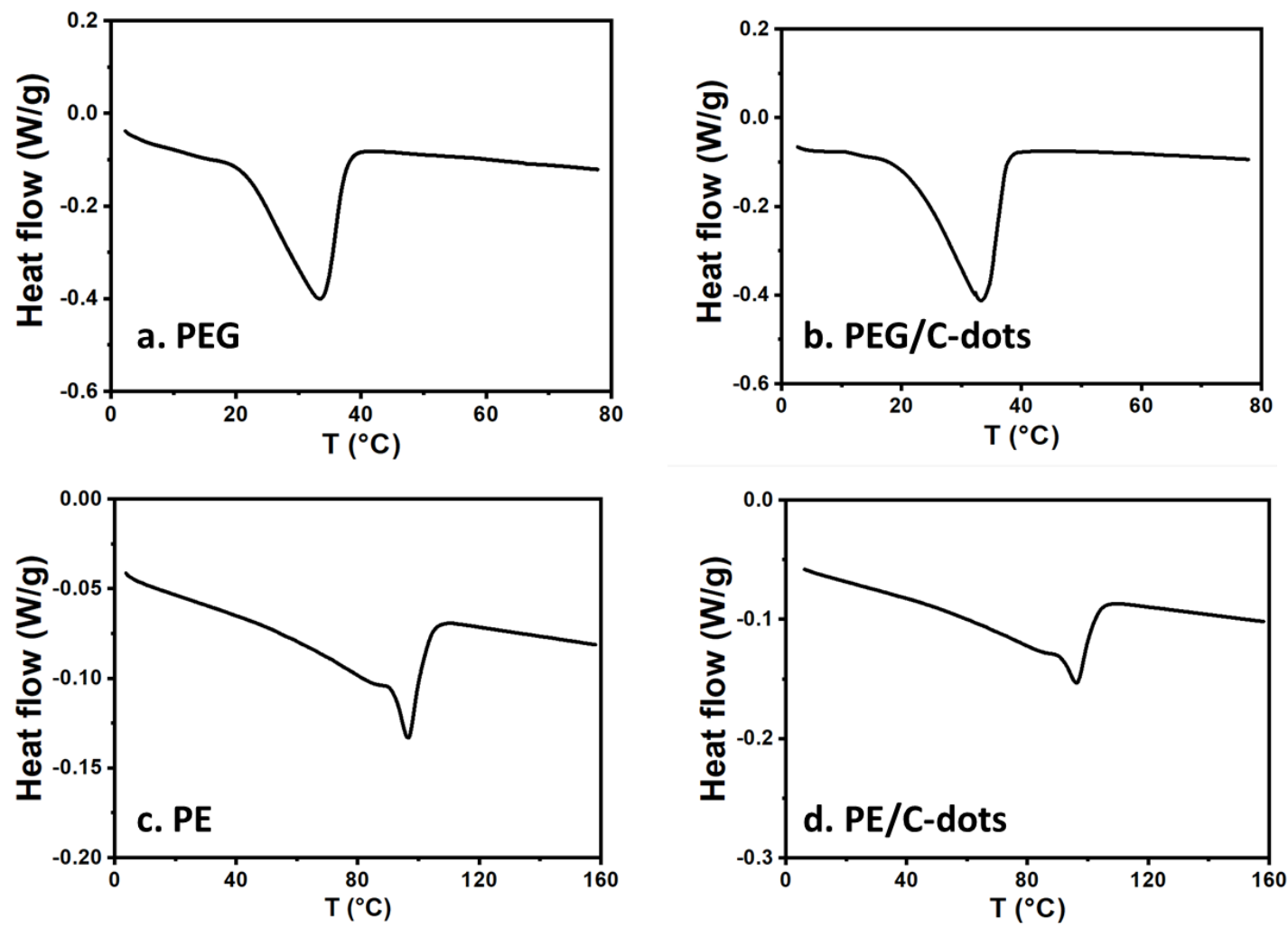

Figure 7. DSC thermographs (second heating cycle) of: (a) PEG, (b) PEG/C-dot, (c) PE, (d) $\mathrm{PE} / \mathrm{C}-\mathrm{dot}$. 

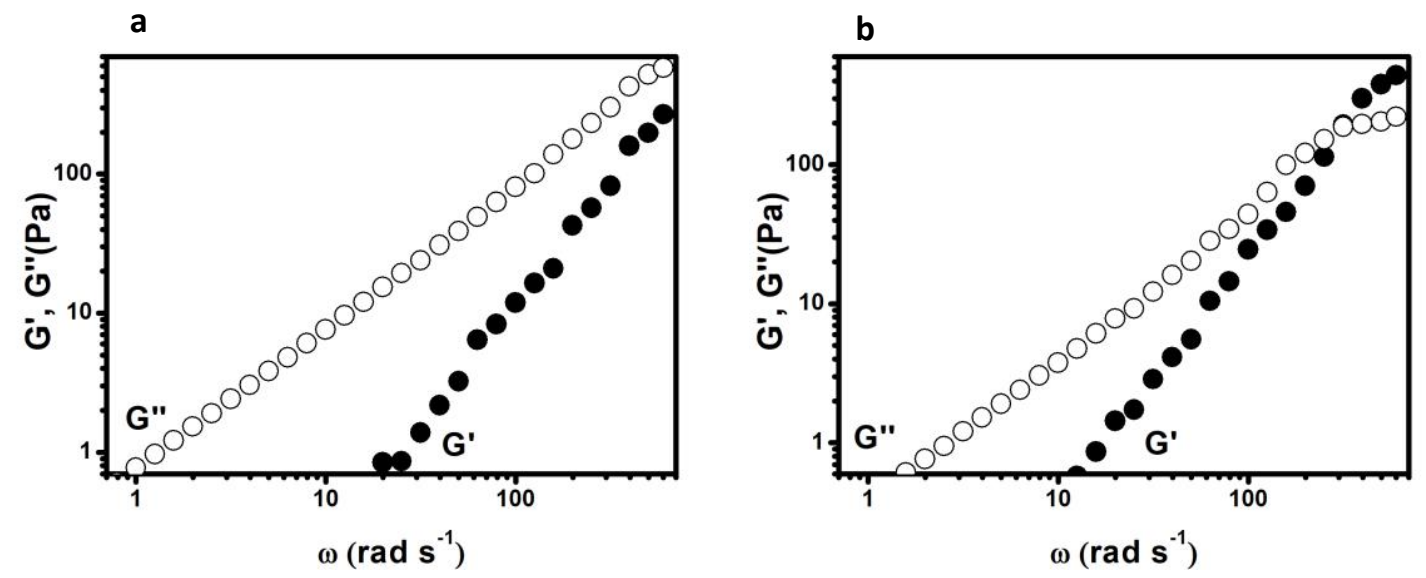

Figure 8. Frequency dependence of the storage (filled symbols) and loss (open symbols) modulus of: (a) PEG and (b) PEG/C-dot at $75^{\circ} \mathrm{C}$. 


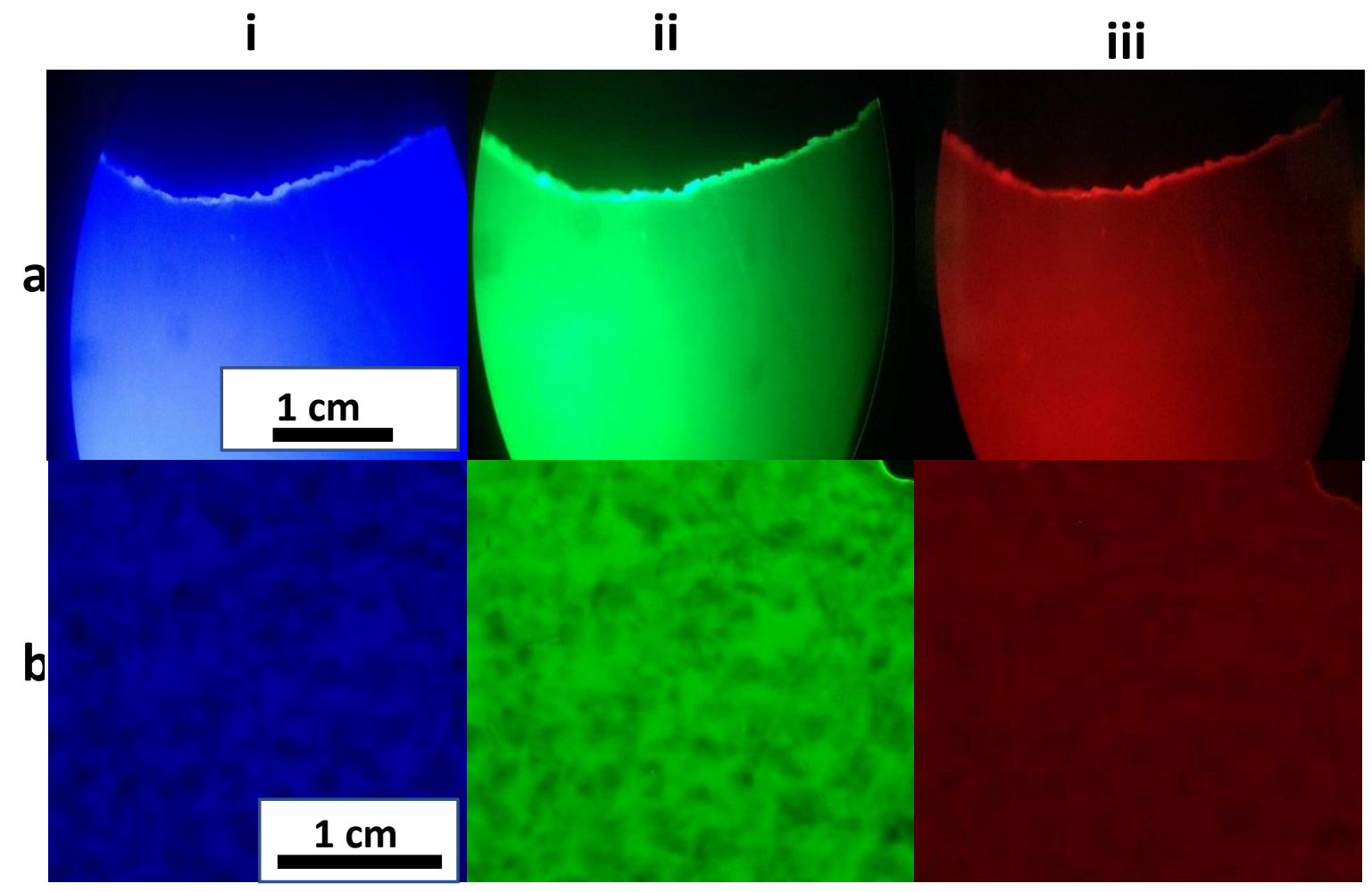

Figure 9. Fluorescence microscopy images of: (a) PEG/ C-dot and (b) PP/C-dot nanocomposite under (i) UV violet, (ii) blue and (iii) green excitation wavelength. 


\section{References}

[1] J. Wang, Y. Liu, Z. Fan, W. Wang, B. Wang, Z. Guo, Ink-based 3D printing technologies for graphene-based materials: a review Advanced Composites and Hybrid Materials 2 (2019) 1-33. doi:10.1007/s42114-018-0067-9

[2] Y. Liu, M. Shi, C. Yan, Q. Zhuo, H. Wu, L. Wang, H. Liu, Z. Guo, Inspired cheese-like biomass-derived carbon with plentiful heteroatoms for high performance energy storage, J. Mater. Sci. 30 (2019) 6583-6592. doi:10.1007/s 10854-019-00965-2

[3] D. Jiang, V. Murugadoss, Y. Wang, J. Lin, T. Ding, Z. Wang, Q. Shao, C. Wang. H. Liu, N. Lu, A. Subramania, Z. Guo, Electromagnetic interference shielding polymers and nanocomposites - a review, Polym. Rev., $59 \quad$ (2019) 280-337. doi:10.1080/15583724.2018.1546737

[4] J. Zhang, P. Li, Z. Zhang, X. Wang, J. Tang, H. Liu, Q. Shao, T. Ding, A. Umar, Z. Guo, Solvent-free graphene liquids: promising candidates for lubricants without the base oil Journal of Colloid and Interface Science 15 (2019) 159-167. doi: 10.1016/j.jcis.2019.01.135

[5] G. Zhu, X. Cui, Y. Zhang, S. Chen, M. Dong, H. Liu, Q. Shao, T. Ding, S. Wu, Z. Guo, Poly (vinyl butyral)/graphene oxide/poly (methylhydrosiloxane) nanocomposite coating for improved aluminum alloy anticorrosion, Polymer, 172 (2019) 415-422. doi: 10.1016/j.polymer.2019.03.056

[6] Z. Yang, X. Hao, S. Chen, Z. Ma, W. Wang, C. Wang, L. Yue, H. Sun, Q. Shao, V. Murugadoss, Z. Guo, Long-term antibacterial stable reduced graphene oxide nanocomposites loaded with cuprous oxide nanoparticles, Journal of Colloid and Interface Science 533 (2019) 13-23. doi: 10.1016/j.jcis.2018.08.053 
[7] S. Li, P. Yang, J. Zhang, W. Xie, C. Wang, C. Liu, Z. Guo, Graphene oxide based dopamine mussel-like cross-linked polyethylene imine nanocomposite coating with enhanced hexavalent uranium adsorption, J. Mater. Chem. A, 7 (2019) 16902-16911. doi: 10.1039/c9ta04562g

[8] R. Ma, Y. Wang, H. Qi, C. Shi, G.Wei, L. Xiao, Z. Huang, S. Liu, H. Yu, C. Teng, H. Liu, V. Murugadoss, J. Zhang, Y. Wang, Z. Guo, Nanocomposite sponges of sodium alginate/graphene oxide/polyvinyl alcohol as potential wound dressing: in vitro and in vivo evaluation, Compos. Part B, 167 (2019) 396-405. doi: 10.1016/j.compositesb.2019.03.006

[9] X. Gong, Y. Liu, Y. Wang, Z. Xie, Q. Dong, M. Dong, H. Liu, Q. Shao, N. Lu, V. Murugadoss, T. Ding, Z. Guo, Amino graphene oxide/dopamine modified aramid fibers: preparation, epoxy nanocomposites and property analysis, Polymer 168 (2019) 131-137. doi: 10.1016/j.polymer.2019.02.021

[10] L. Ma, Y. Zhu, M. Yang, X. Yang, G. Song, Y. Huang, Enhancing interfacial strength of epoxy resin composites via evolving hyperbranched amino-terminated POSS on carbon fiber surface, Compos. Sci. Technol., 170 (2019) 148-156. doi: 10.1016/j.compscitech.2018.12.001

[11] L. Ma, Y. Zhu, P. Feng, G. Song, Y. Huang, H. Liu, J. Zhang, J. Fan, H. Hou, Z. Guo, Reinforcing carbon fiber epoxy composites with triazine derivatives functionalized graphene oxide modified sizing agent, Compos. Part B: Engineering, 176 (2019) 107078. doi: 10.1016/j.compositesb.2019.107078

[12] H. Gu, X. Xu, M. Dong, P. Xie, Q. Shao, R. Fan, C. Liu, S. Wu, R. Wei, Z. Guo, Carbon nanospheres induced high negative permittivity in nanosilver-polydopamine metacomposites, Carbon 147 (2019) 550-558. doi: 10.1016/j.carbon.2019.03.028

[13] S.N. Baker, G.A. Baker, Luminescent Carbon Nanodots: Emergent Nanolights, Angew. Chem . Int. Ed. 49 (2010) 6726-6744. doi:10.1002/anie.200906623. 
[14] K. Hola, Y. Zhang, Y. Wang, E.P. Giannelis, R. Zboril, A.L. Rogach, Carbon dots Emerging light emitters for bioimaging, cancer therapy and optoelectronics, Nano Today. 9 (2014) 590-603. doi:10.1016/j.nantod.2014.09.004.

[15] S.Y. Lim, W. Shen, Z. Gao, Carbon quantum dots and their applications, Chem. Soc. Rev. 44 (2014) 362-381. doi:10.1039/c4cs00269e.

[16] F. Yuan, S. Li, Z. Fan, X. Meng, L. Fan, S. Yang, Shining carbon dots: Synthesis and biomedical and optoelectronic applications, Nano Today. 11 (2016) 565-586. doi:10.1016/j.nantod.2016.08.006.

[17] J.B. Essner, G.A. Baker, The emerging roles of carbon dots in solar photovoltaics: a critical review, Environ. Sci. Nano. 4 (2017) 1216-1263. doi:10.1039/C7EN00179G.

[18] H. Tao, K. Yang, Z. Ma, J. Wan, Y. Zhang, Z. Kang, Z. Liu, In Vivo NIR fluorescence imaging, biodistribution, and toxicology of photoluminescent carbon dots produced from carbon nanotubes and graphite, Small. 8 (2012) 281-290. doi:10.1002/smll.201101706.

[19] A.N. Emam, S.A. Loutfy, A.A. Mostafa, H. Awad, M.B. Mohamed, Cyto-toxicity, biocompatibility and cellular response of carbon dots-plasmonic based nano-hybrids for bioimaging, RSC Adv. 7 (2017) 23502-23514. doi:10.1039/C7RA01423F.

[20] J. Jung, C. H. Lin, Y. J. Yoon, S. T. Malak, Y. Zhai, E. L. Thomas, V. Vardeny, V. V. Tsukruk, Z. Lin, Crafting Core/Graded Shell-Shell Quantum Dots with Suppressed Reabsorption and Tunable Stokes Shift as High Optical Gain Materials Angew. Chem. Int. Ed. 55 (2016) 5071 -5075. doi: 10.1002/anie.201601198.

[21] Y. J. Yoon, Y. Chang, S. Zhang, M. Zhang, S. Pan, Y. He, C. H. Lin, S. Yu, Y. Chen, Z. Wang, Y. Ding, J. Jung, N. Thadhani, V. V. Tsukruk, Z. Kang, Z. Lin, Enabling tailorable optical properties and markedly enhanced stability of perovskite quantum dots by permanently ligating with polymer hairs Adv. Mater. 31 (2019) 1901602. doi:10.1002/adma.201901602. 
[22] H. Huang, S. Yang, Q. Li, Y. Yang, G. Wang, X. You, B. Mao, H. Wang, Y. Ma, P. He, Z. Liu, G. Ding, X. Xie, Electrochemical cutting in weak aqueous electrolyte: the strategy for efficient and controllable preparation of graphene quantum dots Langmuir 34 (2018) 250-258. doi: 10.1021/acs.langmuir.7b03425

[23] D. Pan, J. Zhang, Z. Li, M. Wu, Hydrothermal route for cutting graphene sheets into blue-luminescent graphene quantum dots, Adv. Mater. 22 (2010) 734-738. doi:10.1002/adma.200902825.

[24] J. Peng, W. Gao, B.K. Gupta, Z. Liu, R. Romero-Aburto, L. Ge, L. Song, L.B. Alemany, X. Zhan, G. Gao, S.A. Vithayathil, B.A. Kaipparettu, A.A. Marti, T. Hayashi, J. Zhu, P.M. Ajayan, Graphene quantum dots derived from carbon fibers, Nano Lett. 12 (2011) 844-849.

[25] D.B. Shinde, V.K. Pillai, Electrochemical preparation of luminescent graphene quantum dots from multiwalled carbon nanotubes, Chem. - A Eur. J. 18 (2012) 12522-12528. doi:10.1002/chem.201201043.

[26] Y. Dong, C. Chen, X. Zheng, L. Gao, Z. Cui, H. Yang, C. Guo, Y. Chi, C.M. Li, Onestep and high yield simultaneous preparation of single- and multi-layer graphene quantum dots from CX-72 carbon black, J. Mater. Chem. 22 (2012) 8764-8766. doi:10.1039/c2jm30658a.

[27] X. Zhang, M. Jiang, N. Niu, Z. Chen, S. Li, S. Liu, J. Li, Review of natural productderived carbon dots: from natural products to functional materials, ChemSusChem. 11 (2018) 11-24. doi:10.1002/cssc.201701847.

[28] M.J. Krysmann, A. Kelarakis, E.P. Giannelis, Photoluminescent carbogenic nanoparticles directly derived from crude biomass, Green Chem. 14 (2012) 3141-3145. doi:10.1039/c2gc35907c.

[29] S. Sahu, B. Behera, T.K. Maiti, S. Mohapatra, K. Maiti, S. Mohapatra, T.K. Maiti, S. Mohapatra, Simple one-step synthesis of highly luminescent carbon dots from orange juice: 
application as excellent bio-imaging agents., Chem. Commun. 48 (2012) 8835-8837. doi:10.1039/c2cc33796g.

[30] J. Wang, C.F. Wang, S. Chen, Amphiphilic egg-derived carbon dots: Rapid plasma fabrication, pyrolysis process, and multicolor printing patterns, Angew. Chemie - Int. Ed. 51 (2012) 9297-9301. doi:10.1002/anie.201204381.

[31] H. Qi, M. Teng, M. Liu, S. Liu, J. Li, H. Yu, C. Teng, Z. Huang, H. Liu, Q. Shao, A. Umar, T. Ding, Q. Gao, Z. Guo, Biomass-derived nitrogen-doped carbon quantum dots: highly selective fluorescent probe for detecting $\mathrm{Fe}^{3+}$ ions and tetracyclines, J. Colloid Interf. Sci., 539 (2019) 332-341. doi:10.1016/j.jcis.2018.12.047

[32] A. Jaiswal, S.S. Ghosh, A. Chattopadhyay, One step synthesis of C-dots by microwave mediated caramelization of poly(ethylene glycol), Chem. Commun. 48 (2012) 407-09. doi:10.1039/c1cc15988g.

[33] S. Zhu, J. ZHang, L. Wang, Y. Song, G. Zhang, H. Wang, B. Yang, A general route to make non-conjugated linear polymers luminescent, Chem. Commun. 48 (2012) 10889-91. doi:10.1039/C2CC36080B.

[34] X. Miao, D. Qu, D. Yang, B. Nie, Y. Zhao, H. Fan, Z. Sun, Synthesis of carbon dots with multiple color emission by controlled graphitization and surface functionalization Adv. Mater. 2017, 1704740. doi: 10.1002/adma.201704740

[35] Y. Tian, L. Li, X. Guo, A. Wojtowicz, L. Estevez, M.J. Krysmann, A. Kelarakis, Dramatic photoluminescence quenching in carbon dots induced by cyclic voltammetry, Chem. Commun. 54 (2018) 9067-9070. doi:10.1039/C8CC03617A

[36] K. Dimos, Carbon quantum dots: Surface passivation and functionalization, Curr. Org. Chem. 20 (2016) 682-95. doi:10.2174/1385272819666150730220948.

[37] Y. Sun, B. Zhou, Y. Lin, Quantum-sized carbon dots for bright and colorful photoluminescence, J. Am. Chem. Soc. 128 (2006) 7756-57. doi:10.1021/ja062677d. 
Nano-carrier for gene delivery and bioimaging based on carbon dots with PEI-passivation enhanced fluorescence, $\quad$ Biomaterials. $33 \quad$ (2012) 3604-3613. doi:10.1016/j.biomaterials.2012.01.052.

[39] T. Wen, B. Yang, Y. Guo, J. Sun, C. Zhao, S. Zhang, M. Zhang, Y. Wang, Organosilane-functionalized graphene quantum dots and their encapsulation into bi-layer hollow silica spheres for bioimaging applications, Phys. Chem. Chem. Phys. 16 (2014) 2318823195. doi:10.1039/C4CP03339F.

[40] D. Fernandes, M.J. Krysmann, A. Kelarakis, Carbogenically coated silica nanoparticles and their forensic applications, Chem. Commun. 52 (2016) 3-5. doi:10.1039/c6cc02556k.

[41] D. Fernandes, M.J. Krysmann, A. Kelarakis, Carbon dot based nanopowders and their application for fingerprint recovery, Chem. Commun. 51 (2015) 4902-405. doi:10.1039/C5CC00468C.

[42] C. Shih, P. Chen, G. Lin, C. Wang, H. Chang, Optical and electrochemical applications of silicon- carbon dots / silicon dioxide nanocomposites, ACS Nano. 9 (2015) 312-319. doi:10.1021/nn504787y

[43] W. Liu, S. Xu, Z. Li, R. Liang, M. Wei, D.G. Evans, X. Duan, Layer-by-Layer assembly of carbon dots-based ultrathin films with enhanced quantum yield and temperature sensing performance, Chem. Mater. 28 (2016) 5426-5431. doi:10.1021/acs.chemmater.6b01792.

[44] T. da S. Pinto, L.A. Alves, G. de Azevedo Cardozo, V.H.O. Munhoz, R.M. Verly, F. V. Pereira, J.P. de Mesquita, Layer-by-layer self-assembly for carbon dots/chitosan-based multilayer: Morphology, thickness and molecular interactions, Mater. Chem. Phys. 186 (2017) 81-89. doi:10.1016/j.matchemphys.2016.10.032. 
[45] S.K. Bhunia, S. Nandi, R. Shikler, R. Jelinek, Tuneable light-emitting carbondot/polymer flexible films prepared through one-pot synthesis, Nanoscale. 8 (2016) 34003406. doi:10.1039/C5NR08400H.

[46] X. Wang, J. Zhang, W. Zou, R. Wang, Facile synthesis of polyaniline/carbon dot nanocomposites and their application as a fluorescent probe to detect mercury, RSC Adv. 5 (2015) 41914-19. doi:10.1039/C5RA03832D.

[47] K. Jiang, S. Sun, L. Zhang, Y. Lu, A. Wu, C. Cai, H. Lin, Red, green, and blue luminescence by carbon dots: Full-color emission tuning and multicolor cellular imaging, Angew. Chemie - Int. Ed. 54 (2015) 5360-63. doi:10.1002/anie.201501193.

[48] J.J. Huang, Z.F. Zhong, M.Z. Rong, X. Zhou, X.D. Chen, M.Q. Zhang, An easy approach of preparing strongly luminescent carbon dots and their polymer based composites for enhancing solar cell efficiency, Carbon 70 (2014) 190-198. doi:10.1016/j.carbon.2013.12.092. [49] X. Fu, Y. Yu, J. Feng, K. Ming, Fabrication of transparent and photoluminescent poly(vinyl butyral)/carbon dots nanocomposite thin film, Mater.Res.Express 2 (2015) 026403. doi:10.1088/2053-1591/2/2/026403

[50] Y. Zhou, S. K. Sharma, Z. Peng, R. M. Leblanc, Polymers in carbon dots: a review Polymers 92 (2017) 67. doi:10.3390/polym9020067

[51] A. Pal, Md Palashuddin, A. Chattopadhyay, Conducting carbon dot-polypyrrole nanocomposite for sensitive detection of picric acid, ACS Appl. Mater. Interfaces, 8 (2016) 5758-5762. doi: 10.1021/acsami.5b11572.

[52] P.R. Sreenath, S. Singh, M.S. Satyanarayana, P. Das, K. Dinesh Kumar, Carbon dot unique reinforcing filler for polymer with special reference to physico-mechanical properties, Polymer,112 (2017) 189-200. doi:10.1016/j.polymer.2017.02.014. 
[53] W. Liu, C. Li, X. Sun, W. Pan, G. Yu, J. Wang, Highly crystalline carbon dots from fresh tomato: UV emission and quantum confinement, Nanotechnology 28 (2017), Article ID 485705. doi: 10.1088/1361-6528/aa900b

[54] K. M. Tripathi, T. S.Tran, T. T.Tung, D. Losic, T. Kim, Water soluble fluorescent Carbon nanodots from biosource for cells imaging, J. Nanomat., (2017) Article ID 7029731. doi:10.1155/2017/7029731

[55] X. Dong, Y. Su, H. Geng, Z. Li, C. Yang, X. Li, Y. Zhang, Fast one-step synthesis of Ndoped carbon dots by pyrolyzing ethanolamine, J. Mater. Chem. C. 2 (2014) 7477-7481. doi:10.1039/C4TC01139B.

[56] M. Chen, W. Wang, X. Wu, One-pot green synthesis of water-soluble carbon nanodots with multicolor photoluminescence from polyethylene glycol, J. Mater. Chem. B. 2 (2014) 3937-3945. doi:10.1039/C4TB00292J.

[57] H. Li, J. Liu, S. Guo, Y. Zhang, H. Huang, Y. Liu, Z. Kang, Carbon dots from PEG for highly sensitive detection of levodopa, J. Mater. Chem. B. 3 (2015) 2378-2387. doi:10.1039/C4TB01983K.

[58] D.L. Snavely, J. Dubsky, Near-IR spectra of polyethylene, polyethylene glycol, and polyvinylethyl ether, J. Polym. Sci. Part A Polym. Chem. 34 (1996) 2575-2579. doi:10.1002/(SICI)1099-0518(19960930)34:13<2575::AID-POLA3>3.0.CO;2-R.

[59] V. Ţucureanu, A. Matei, A.M. Avram, FTIR spectroscopy for carbon family study, Crit. Rev. Anal. Chem. 46 (2016) 502-520. doi:10.1080/10408347.2016.1157013.

[60] M.M. Coleman, P.C. Painter, Fourier transform infrared studies of polymeric materials, Journal of Macromolecular Science Part C. $31 \quad$ (1977) 197-278. doi:10.1080/00222357608064318 
[61] R.P. Wool, R.S. Bretzlafft, B.Y. Li, C.H. Wang, R.H, Boyd, Infrared and Raman spectroscopy of stressed polyethylene. J. Polym. Sci. Part B Polym. Phys. 24 (1986) 10391066. doi:10.1002/polb.1986.090240508

[62] A.B. Bourlinos, A. Stassinopoulos, D. Anglos, R. Zboril, M. Karakassides, E.P. Giannelis, Surface functionalized carbogenic quantum dots, Small. 4 (2008) 455-458. doi:10.1002/smll.200700578.

[63] A. Kelarakis, From highly graphitic to amorphous carbon dots: A critical review, MRS Energy Sustain. 1 (2014) 1-15. doi:10.1557/mre.2014.7.

[64] M.J. Krysmann, A. Kelarakis, P. Dallas, E.P. Giannelis, Formation mechanism of carbogenic nanoparticles with dual photoluminescence emission, J. Am. Chem. Soc. 134 (2012) 747-750. doi:10.1021/ja204661r.

[65] S. Zhu, Y. Song, X. Zhao, J. Shao, J. Zhang, B. Yang, The photoluminescence mechanism in carbon dots (graphene quantum dots, carbon nanodots, and polymer dots): current state and future perspective, Nano Res. 8 (2015) 355-81. doi:10.1007/s12274-0140644-3.

[66] A. Kelarakis, Graphene quantum dots: In the crossroad of graphene, quantum dots and carbogenic nanoparticles, Curr. Opin. Colloid Interface Sci. 20 (2015) 354-361. doi:10.1016/j.cocis.2015.11.001.

[67] S. Yang, J. Sun, X. Li, W. Zhou, Z. Wang, P. He, G. Ding, X. Xie, Z. Kang, M. Jiang, Large-scale fabrication of heavy doped carbon quantum dots with tunable-photoluminescence and sensitive fluorescence detection, J. Mater. Chem. A. 2 (2014) 8660-8667. doi:10.1039/c4ta00860j.

[68] A. Kelarakis, S. Hayrapetyan, S. Ansari, J. Fang, L. Estevez, E. P. Giannelis, Clay nanocomposites based on poly(vinylidene fluoride-co-hexafluoropropylene): Structure and properties, Polymer 51 (2010) 469-474. doi:10.1016/j.polymer.2009.11.057 
[69] X. Zheng, Q. Xu, Comparison study of morphology and crystallization behavior of polyethylene and poly(ethylene oxide) on single-walled carbon nanotubes, The Journal of Physical Chemistry B 114 (2010) 9435-9444. doi: 10.1021/jp103932b

[70] E. Hackett, E. Manias, E. P. Giannelis, Computer simulation studies of PEO/layer silicate nanocomposites, Chemistry of Materials 12 (2000) 2161-2167. doi: 10.1021/cm990676x

[71] L. Zhou, B. He, J. Huang, Amphibious fluorescent carbon dots: one-step green synthesis and application for light-emitting polymer nanocomposites, Chem.Commun.,49 (2013) 80788080, doi: 10.1039/C3CC43295E

[72] F. Ciardelli, G. Ruggeri, A. Pucci, Dye-containing polymers: methods for preparation of mechanochromic materials, Chem. Soc. Rev., 42 (2013), 857-870, doi:10.1039/C2CS35414D [73] A. Kelarakis, M.J. Krysmann, E.P. Giannelis, Thermoreversible gelation in poly(ethylene oxide)/carbon black hybrid melts, Polymer 55 (2014) 6278-6281. doi:10.1016/j.polymer.2014.10.023.

[74] A. Anand, B. Unnikrishnan, S.-C. Wei, C. P. Chou, L.-Z. Zhang, C.-C. Huang, Graphene oxide and carbon dots as broad-spectrum antimicrobial agents - a mini review, Nanoscale horizons 5 (2019) 117-137. doi: 10.1039/C8NH00174J

[75] G. A. M. Hutton, B.C. M. Martindale, E. Reisner, Carbon dots as photosensitisers for solar-driven catalysis, Chem. Soc. Rev., 46 (2017) 6111-6123. doi: 10.1039/c7cs00235a. 